\title{
The Parable of the Juggler
}

\section{Joel Brind}

Behold: A juggler went forth to juggle. He juggled five smooth stones at a time, which he took from a full basket of stones at his right hand.

And as he juggled the stones in the air, he would deposit them into a basket, which was empty, that was at his left hand, depositing them one-by-one, even as he took new stones from the basket at his right hand one-by-one, such that five stones were always being thrown up into the air and juggled.

While the stones were being juggled, they were under the constant watchful eye of the juggler, lest at any time they should fall to the ground and be scattered, and the act abruptly ended upon the instant;

And the juggler's act was complete when the basket at his right hand was empty, and the basket at his left hand was filled with the stones that had been juggled.

And when he juggled before his audiences, the juggler performed his act in a darkened theater, and with stones that glowed in the dark;

Therefore the stones, whilst being juggled, traced a beautiful and intricate pattern in the air, but the juggler himself was invisible to the audience.

And certain of those in the audience that witnessed the juggler's performance marveled so at the movement of the glowing stones and the complex and beautiful pattern that they traced in the air,

That they attended many performances and devoted their lives to observing them, such that they became expert observers of the juggling act;

And the Experts observed that, with only slight variations, the pattern that the glowing stones made in the air as they were being juggled, remained the same, even as new stones were being added from the basket at the right, and 
removed to the basket at the left, such that the five balls in the air were never the same ones from moment to moment.

And they also observed, as they followed each stone one-by-one, from the basket at the right, to being juggled in the air, to the basket at the left; that each stone remained exactly the same in every observable respect;

Therefore they understood that the properties of the stones themselves were not altered in any way by the act of being juggled; that they had no different properties when in the air to which they were thrown up and participating in the making of the intricate pattern of light, than they had when in either basket.

And because the Experts could not see the juggler himself, they said, "There is no juggler here, but the properties of these stones themselves must cause them to move about in the air in these complex ways, and to form these intricate and beautiful patterns."

The common people understood that a juggler must be performing the act, and that he must be watching carefully at every moment, lest the stones all fall and be scattered,

But the Experts, believing in only what they could see, insisted there was no juggler; for to admit the existence of the juggler, they would have to admit that he was more clever and skillful than they.

And the Experts wrote many books about the nature of the stones that were juggled, and the patterns that they made in the air, for they had developed such precise instruments to observe them.

The Experts' technology enabled them to measure the weight and pattern of flight of the stones so precisely, and to predict their rise and fall with such accuracy, that the people marveled at their skill.

The Experts even developed such marvelous devices that could act at a distance and even slightly change the course of individual stones, slightly changing the pattern they traced in the air.

So impressive was the Experts' technology that they convinced the rulers of the kingdom-and many of the people who attended their universities - of their doctrine that there was no juggler; that the stones moved in these patterns all on their own, without anyone to direct and attend to their every move.

And so the people were taught that all the complex and beautiful movements of the stones were the result of random interactions enabled by the inherent properties of the stones themselves. 
And so the people raised their children to believe there was nothing behind, nor before, nor after the show of light, for only the intricate, dazzling and beautiful pattern of light made by the stones could be seen, and of course, the inanimate stones themselves.

And the people came to depend upon the Experts for the truth of everything that happened in their world, and even the truth of their own existence.

And they would not eat, nor drink, nor act, nor deal with illness or injury, without the advice and direction of the Experts.

And they came to believe that nothing really existed-even themselvesbeyond what could be seen, for so the Experts had taught them.

And therefore the people no longer understood nor even remembered the laws and principles upon which their own civilization depended. And their civilization fell, and great was the fall of it. 